\title{
RECURSOS HUMANOS DAS UNIDADES DE TERAPIA INTENSIVA DO MUNICÍPIO DE SÃO PAULO*
}

\author{
Ana Maria Kazue Miyadahira** \\ Diná de Almeida Lopes Monteiro da Cruz** \\ Katia Grillo Padilha** \\ Miako Kimura** \\ Regina Marcia Cardoso de Sousa**
}

MIYADAHIRA, A.M.K.; CRUZ, D.de A.L.M.da; PADILHA, K.G.; KIMURA, M.; SOUSA, R.M.C.de. Recursos humanos das unidades de terapia intensiva do município de São Paulo. Rev.latino-am.enfermagem, Ribeirão Preto, v. 7, n. 5, p. 15-23, dezembro 1999.

O estudo teve como objetivo investigar aspectos das UTIs do Município de São Paulo, no que se refere à composição da equipe assistencial, características da equipe de enfermagem e a caracterização dos enfermeiros. Os dados foram coletados através de 47 questionários distribuidos em 32 hospitais sorteados. Os resultados mostram que: os períodos da manhã e da tarde contaram com maior número de pessoal de todas as categorias da equipe assistencial, a maioria do pessoal de enfermagem tem jornada de trabalho de 36 horas, o salário dos enfermeiros variou de 700 a 1500 reais e que 66,1\% freqüentaram curso de PósGraduação. Concluiu-se que a equipe de enfermagem correspondeu a 79,2\% da equipe assistencial.

UNITERMOS: recursos humanos, unidade de cuidados intensivos (UCI /UTI)

\section{INTRODUÇÃO}

Segundo GOMES (1988) Unidade de Terapia Intensiva (UTI) é uma área hospitalar em que os pacientes em estado grave podem ser tratados por uma equipe qualificada, sob as melhores condições possíveis: centralização de esforços e coordenação de atividades.

Lembra ainda, que a UTI não é apenas um serviço com equipamento especial, implica uma atitude particular da equipe que ali trabalha. $O$ fator primordial é o relacionamento interpessoal, isto é, um contexto em que os recursos humanos ali alocados ofereçam ao paciente e família, segurança e um efetivo apoio emocional, aliados a uma atitude orientada para o aproveitamento dos recursos tecnológicos existentes.

Quando se trata de recursos humanos de UTI, é importante salientar o papel da equipe de enfermagem dentro da equipe de saúde e em especial do profissional enfermeiro a quem por lei ( $\mathrm{n}^{\circ} 7498 / 86 \mathrm{em}$ seu artigo 11), compete, privativamente, prestar "cuidados diretos de enfermagem a pacientes graves, com risco de vida" (BRASIL,1986).

Assim para se proporcionar uma assistência de enfermagem com qualidade é essencial não só uma qualificação específica do enfermeiro, mas também um contingente adequado deste profissional e sua equipe para garantir um padrão satisfatório de assistência.

KOCK \& MULLER (1991) baseados em dados disponíveis no Conselho Regional de Enfermagem do Estado do Paraná sobre os problemas dos serviços de enfermagem e frente a Legislação, Código de Ética, especificaram como número mínimo da equipe de enfermagem, para as áreas consideradas críticas como a UTI, que para 10 leitos são necessários 20 elementos desta equipe, sendo $30 \%$ enfermeiros e $70 \%$ de técnicos ou auxiliares de enfermagem; recomendam ainda, a não contratação do atendente de enfermagem.

Entretanto, os resultados preliminares apresentados pelo Conselho Regional de Enfermagem do Estado de São Paulo PIMENTEL et al. (1996), mostram que em relação a equipe de enfermagem, quando se compara o levantamento de 1982 e 1996, houve aumento quantitativo em quase todas as categorias da equipe de enfermagem, com exceção do atendente de enfermagem que passou de $67,0 \%$ para $38,0 \%$, o que corresponde a um decréscimo de $28,0 \%$. Isto se deve provavelmente à promulgação da Lei $\mathrm{n}^{\circ} 7.498$ em 1986, que em seu artigo $2^{\circ}$, parágrafo único, não reconhece essa categoria,

* Parte do Projeto Integrado "Recursos assistenciais em UTI implicações na qualidade de assistência", financiado pelo CNPq (Processo No 520 768/94-9)

** Professor Doutor do Departamento de Enfermagem Médico Cirúrgica da Escola de Enfermagem da Universidade de São Paulo 
indicando portanto, exercício ilegal das atividades de enfermagem. Já para o profissional enfermeiro houve um incremento de $2,7 \%$, passando de $8,3 \%$ para $11,0 \%$.

Face à inexistência de dados sobre recursos humanos alocados nas UTIs em geral e, em particular, nas do Município de São Paulo, o presente estudo tem como objetivo investigar alguns aspectos desta realidade, no que se refere à composição da equipe assistencial; características da equipe de enfermagem em relação à jornada de trabalho, turnos e rodízios, carga horária semanal e salário inicial, além da caracterização dos enfermeiros quanto aos dados de identificação pessoal, formação e experiência profissional.

\section{MATERIAL E MÉTODO}

\subsection{Hospitais e amostra}

Utilizando-se dos dados do Cadastro de Hospitais com UTI do Centro de Informações de Saúde (CIS), da Secretaria de Estado de Saúde do Estado de São Paulo, de 1992, constatou-se a existência de 88 hospitais com UTI no Município de São Paulo.

Foi feita uma amostragem casual estratificada, considerando-se os 8 Escritórios Regionais de Saúde (ERSA) integrantes do Sistema Único de Saúde (SUS), do Município de São Paulo (Figura 1). Estabeleceu-se como critério para definição da amostra, o sorteio de $40 \%$ dos hospitais de cada ERSA, obtendo-se desta forma um total de 39 hospitais.

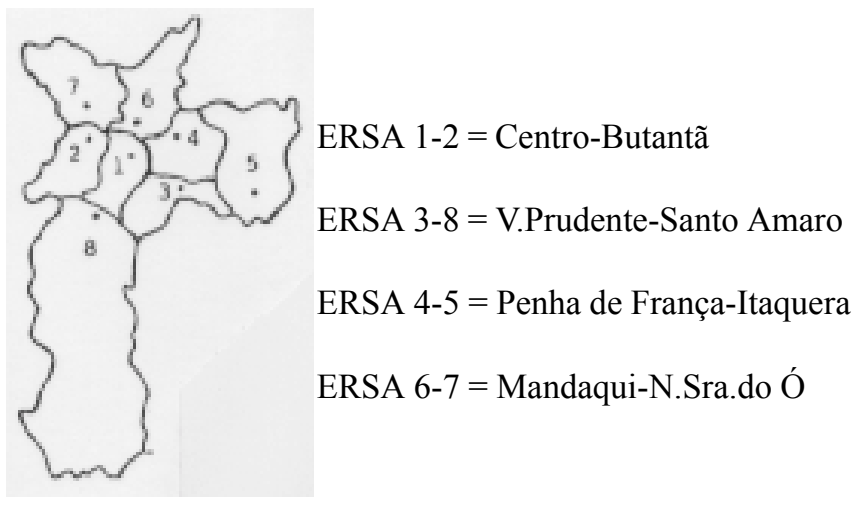

Figura 1 - Mapa do Município de São Paulo com os limites dos 8 Escritórios Regionais de Saúde. São Paulo,1994/1995

A partir de janeiro de 1995, houve um reagrupamento dos ERSAs em Núcleos Regionais de Saúde (NRS). Assim, o que era ERSA 1 e 2 (Centro e Butantã) é atualmente NRS I - Centro-Oeste; o ERSA 3 e 8 (Vila Prudente e Santo Amaro) é o NRS II - Sul; o ERSA 4 e 5 (Penha de França e Itaquera) é NRS III Leste e o ERSA 6 e 7 (Mandaqui e Nossa Senhora do Ó) é NRS IV - Norte.

\subsection{Coleta de dados}

\subsubsection{Instrumento}

Os dados foram coletados no período de julho de 1994 a maio de 1995.

Foi elaborado um questionário, especificamente para este fim, que visava obter dados dos recursos humanos das UTIs do Município de São Paulo que fizeram parte da amostra selecionada, conforme descrição no subtítulo anterior.

Os aspectos dos recursos humanos analisados neste artigo foram: composição da equipe assistencial; caracterização da equipe de enfermagem em relação à jornada de trabalho, turnos de trabalho e rodízios, carga horária semanal e salário inicial; caracterização dos enfermeiros quanto aos dados de identificação, formação e experiência profissional.

\subsubsection{Operacionalização}

A partir da definição dos 39 hospitais sorteados, componentes da amostra, foi feito contato por telefone com os responsáveis pelo Serviço de Enfermagem do hospital ou pela(s) UTI(s). Nesta oportunidade foi solicitada autorização para coleta de dados, após os esclarecimentos necessários (consentimento da instituição) acerca dos objetivos e importância para o grupo de pesquisa em UTI da Escola de Enfermagem da USP.

Os questionários foram entregues e preenchidos pelos enfermeiros responsáveis pelas UTIs destes hospitais.

Das 39 instituições com UTI do Município de São Paulo sorteadas, obteve-se um total de 32 hospitais, pois 7 foram excluídos da amostra por não terem respondido ao questionário no prazo determinado ou por não autorizarem a coleta de dados. Nestes 32 hospitais foram distribuídos 47 questionários e destes conseguiuse o retorno de $43(91,5 \%)$.

\subsection{Tratamento estatístico dos dados}

Os resultados obtidos foram analisados sob a forma de números absolutos e relativos, sendo apresentados em forma de tabelas, quadros e figuras. 
Os dados serão apresentados e discutidos considerando a equipe assistencial, a equipe de enfermagem e o perfil dos enfermeiros que atuam nas UTIs estudadas.
Os dados referentes às UTIs e sua dotação da equipe assistencial e turno de trabalho estão apresentados na Tabela 1.

Tabela 1 - Distribuição das UTIs segundo dotação dos componentes da equipe assistencial e turnos de trabalho. São Paulo, 1994/1995

\begin{tabular}{l|cccccccccccccccc}
\hline \multicolumn{1}{c|}{ Turnos } & \multicolumn{4}{c}{ M } & \multicolumn{1}{c}{ T } & \multicolumn{1}{c}{ NP } & \multicolumn{1}{c}{ NI } \\
Dotação & Sim & Não & N & EB & Sim & Não & N & EB & Sim & Não & N & EB & Sim & Não & N & EB \\
\hline * Enf.Chefe & & & & & & & & & & & & & & & \\
*Enf.Assistencial & 31 & 10 & 1 & 1 & 5 & 36 & 1 & 1 & 2 & 39 & 1 & 1 & 2 & 39 & 1 & 1 \\
* Téc.Enfermagem & 35 & 6 & 1 & 1 & 34 & 6 & 1 & 2 & 34 & 7 & 1 & 1 & 33 & 8 & 1 & 1 \\
* Aux.Enfermagem & 8 & 33 & 1 & 1 & 10 & 31 & 1 & 1 & 8 & 33 & 1 & 1 & 6 & 35 & 1 & 1 \\
*Atend.Enfermagem & 41 & - & 1 & 1 & 41 & - & 1 & 1 & 40 & 1 & 1 & 1 & 40 & 1 & 1 & 1 \\
* Médico & 22 & 19 & 1 & 1 & 19 & 22 & 1 & 1 & 17 & 23 & 1 & 2 & 17 & 23 & 1 & 1 \\
*Médico Residente & 39 & - & 1 & 3 & 39 & - & 1 & 3 & 38 & 1 & 1 & 3 & 38 & - & 1 & 3 \\
*Fisioterapeuta & 2 & 39 & 1 & 1 & 2 & 39 & 1 & 1 & 2 & 39 & 1 & 1 & 2 & 39 & 1 & 1 \\
* Nutricionista & 22 & 19 & 1 & 1 & 21 & 20 & 1 & 1 & 10 & 31 & 1 & 1 & 10 & 31 & 1 & 1 \\
*Assist.Social & 11 & 30 & 1 & 1 & 6 & 35 & 1 & 1 & 1 & 40 & 1 & 1 & 1 & 40 & 1 & 1 \\
& 10 & 31 & 1 & 1 & 4 & 37 & 1 & 1 & 1 & 40 & 1 & 1 & 1 & 40 & 1 & 1 \\
\hline
\end{tabular}

Legenda: M: Manhã; T: Tarde; NP: Noite Par; NI: Noite Impar; N: Nulo; EB: Em branco

Enf.: Enfermeiro; Téc.: Técnico; Aux.: Auxiliar; Atend.: Atendente

A Tabela 1 mostra que, nas UTIs do Município de São Paulo, o auxiliar de enfermagem foi o profissional mais presente tendo sido encontrado em 41 das 43 UTIs, nos turnos da manhã e tarde e em 40 das UTIs, no turno da noite. Segue-se a ele o médico, presente em 39 unidades no período diurno e 38 , no noturno. Apenas duas das UTIs respondentes contavam com médico residente.

Em relação ao enfermeiro, esteve mais presente no turno da manhã, tanto o assistencial (35) quanto o chefe (31), sendo que a grande maioria das UTIs não contam com o enfermeiro chefe nos turnos da tarde e da noite. Quanto ao enfermeiro assistencial, não foi encontrado em todas as UTIs, conforme o desejado, embora grande parte delas tenham informado contar com este profissional em todos os turnos de trabalho.

Em relação ao turno de trabalho, os períodos da manhã e da tarde contaram com maior número de pessoal de todas as categorias da equipe assistencial.

Apesar da restrição imposta pela Lei do Exercício Profissional de Enfermagem quanto ao atendente, verifica-se a sua presença em muitas das UTIs, em todos os turnos, sobrepujando inclusive os técnicos de enfermagem, categoria ainda pouco empregada nas UTIs.

Quanto ao fisioterapeuta, foi equivalente o número de UTIs com e sem este profissional, constatandose a sua presença muito mais no período diurno do que no noturno.

Nutricionistas e assistentes sociais foram os profissionais menos presentes na composição da equipe assistencial das UTIs respondentes.

O número insuficiente de enfermeiros com habilidade e experiência para prestar cuidados altamente qualificados nas UTIs, levou a Associação Americana de Enfermagem em Cuidados Intensivos (AACN) e a Sociedade Médica Americana de Cuidados Intensivos (SCCM) a rediscutir juntas meios de solucionar esta crise do cuidado ao paciente crítico, elaborando modelo de "prática colaborativa" na qual cada profissional teria autonomia de decidir questões relativas à sua área de atuação (CARLSON, 1989). Este mesmo autor descreve que muitas questões são de difíceis soluções, mas que o esforço conjunto ao prenunciar uma nova era com o advento deste modelo de prática colaborativa do cuidado à beira do leito, pode amenizar estas dificuldades. 
Tabela 2 - Distribuição dos componentes da equipe assistencial segundo os turnos de trabalho. São Paulo, 1994/ 1995

\begin{tabular}{l|cccc|cc}
\hline \multicolumn{1}{c|}{ Turnos } & \multicolumn{1}{c|}{} & & \multicolumn{2}{c}{ Total } \\
Compone ntes & M & T & NP & NI & $\mathbf{n}^{\mathbf{0}}$ & \% \\
\hline * Enf.Chefe & 31 & 5 & 2 & 2 & 40 & 2,4 \\
* Enf.Assistencial & 58 & 59 & 47 & 47 & 211 & 12,6 \\
* Téc.Enfermagem & 13 & 18 & 15 & 8 & 54 & 3,2 \\
* Aux.Enfermagem & 250 & 233 & 214 & 215 & 912 & 54,4 \\
*Atend.Enfermagem & 30 & 25 & 29 & 27 & 111 & 6,6 \\
* Médico & 62 & 62 & 47 & 47 & 218 & 13,1 \\
* Médico Residente & 6 & 6 & 3 & 3 & 18 & 1,1 \\
*Fisioterapeuta & 26 & 25 & 11 & 11 & 73 & 4,3 \\
* Nutricionista & 13 & 7 & 1 & 1 & 22 & 1,3 \\
*Assist.Social & 10 & 4 & 1 & 1 & 16 & 1,0 \\
\hline Total & $499(29,8)$ & $444(26,5)$ & $370(22,1)$ & $362(21,0)$ & 1675 & $(100,0)$ \\
\hline
\end{tabular}

Legenda: M: Manhã; T: Tarde; NP: Noite Par; NI: Noite Ímpar

Pela Tabela 2 observa-se que dos componentes da equipe assistencial o auxiliar de enfermagem é o profissional numericamente mais presente, perfazendo um total de 912 (54,4\%) elementos, seguidos do médico e do enfermeiro assistencial com respectivamente 218 $(13,1 \%)$ elementos e $211(12,6 \%)$ elementos. Ressaltese que, no conjunto da equipe assistencial, a equipe de enfermagem representou $79,2 \%$ dos componentes identificados nas UTIs pesquisadas.

Em estudo feito por ALCALA et al. (1977), na Secretaria de Higiene e Saúde do Município, estabeleceram que para a Unidade de Terapia Intensiva a proporção das categorias profissionais de enfermagem deveria ser de $40 \%$ enfermeiros e $60 \%$ auxiliares de enfermagem.

O Instituto Nacional de Assistência Médica da Previdência Social, em 1988, fez uma estimativa da proporção das categorias profissionais para UTI de 60 enfermeiros e 40 técnicos de enfermagem (BRASIL, 1988).

Já, KOCK \& MULLER (1991) do Conselho Regional de Enfermagem do Paraná recomendam para UTIs uma proporção de 30 enfermeiros e 70 técnicos ou auxiliares de enfermagem.

Neste estudo a proporção foi de $20,6 \%$ de enfermeiros (chefe ou assistencial) e 79,4\% de técnicos ou auxiliares de enfermagem. Cabe citar ainda que nas UTIs estudadas ainda existe um contingente de $8,4 \%$ de atendentes de enfermagem que nenhum dos estudos acima mencionados faz referência a esta categoria.

Em relação ao turno de trabalho, os períodos da manhã e da tarde contaram com maior número de pessoal de todas as categorias da equipe assistencial.

\subsection{Dados relacionados à equipe de enfermagem}

No que diz respeito a jornada de trabalho semanal do pessoal de enfermagem verificou-se que, das 43 UTIs deste estudo o resultado obtido foi o seguinte: em 18 $(41,9 \%)$ delas a enfermeira chefe tinha a carga horária de 40 horas semanais; em $26(60,5 \%)$ das UTIs a enfermeira assistencial tinha a carga horária semanal de 36 horas, sendo que o técnico, o auxiliar e o atendente de enfermagem, tinham esta mesma carga horária de 36 horas semanais em, respectivamente 9 (20,9\%), $27(62,8 \%)$ e 15 (34,9\%) das UTIs. Portanto, estes dados nos permitem inferir que um grande contingente de pessoal de enfermagem, destas UTIs, tem jornada de trabalho de 36 horas.

Em relação ao rodízio de turno da equipe de enfermagem os dados estão representados na Figura 2.

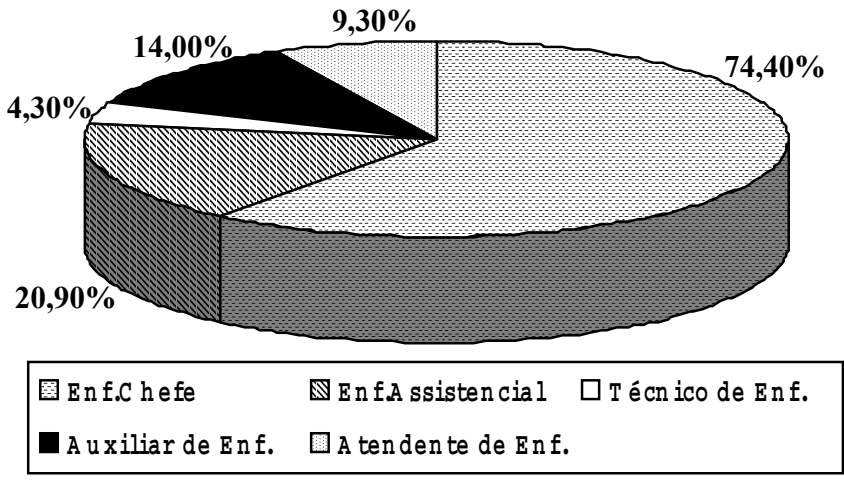

Figura 2 - Distribuição das UTIs com presença de rodízio de turno da equipe de enfermagem. São Paulo, 1994/1995

Quanto a presença ou não de rodízio de turno 
para o pessoal de enfermagem, observa-se pela Figura 2 que na grande maioria, ou seja, $32(74,4 \%)$ das UTIs o enfermeiro chefe faz rodízio, sendo que para as demais categorias, predominaram as unidades que adotam o rodízio de plantões para as diferentes categorias da equipe de enfermagem. Assim, em 30 (69,8\%) das UTIs não havia rodízio para o enfermeiro assistencial, assim como em $11(25,5 \%)$ das UTIs para o técnico de enfermagem, em $34(79,1 \%)$ das UTIs para o auxiliar de enfermagem e em $21(48,9 \%)$ das UTIs para o atendente de enfermagem.

Em relação a duração dos turnos de trabalho da equipe de enfermagem, obteve-se que em $19(44,2 \%)$ das
UTIs o enfermeiro chefe tinha jornada de trabalho de 8 horas por dia, sendo que nesta mesma proporção de UTIs o enfermeiro assistencial fazia turnos com duração de 6/ 6/12 horas (manhã/tarde/noite). Já para o técnico de enfermagem, em número igual de $3(7,0 \%)$ das UTIs os turnos tinham duração de 6/6/12 e 12/0/12 horas. Em 17 $(39,6 \%)$ das UTIs predominaram, para o auxiliar de enfermagem, os turnos com duração de 6/6/12 horas e para o atendente de enfermagem, os plantões de 6/6/12 e 12/0/12 horas, em igual número de 7 (16,3\%) unidades.

Quanto a relação numérica entre funcionários da equipe de enfermagem/pacientes, nos turnos de trabalho obteve-se os seguintes dados (Tabela 3 ).

Tabela 3 - Distribuição das UTIs segundo a relação numérica entre funcionários da equipe de enfermagem/ paciente, nos turnos de trabalho. São Paulo, 1994/1995

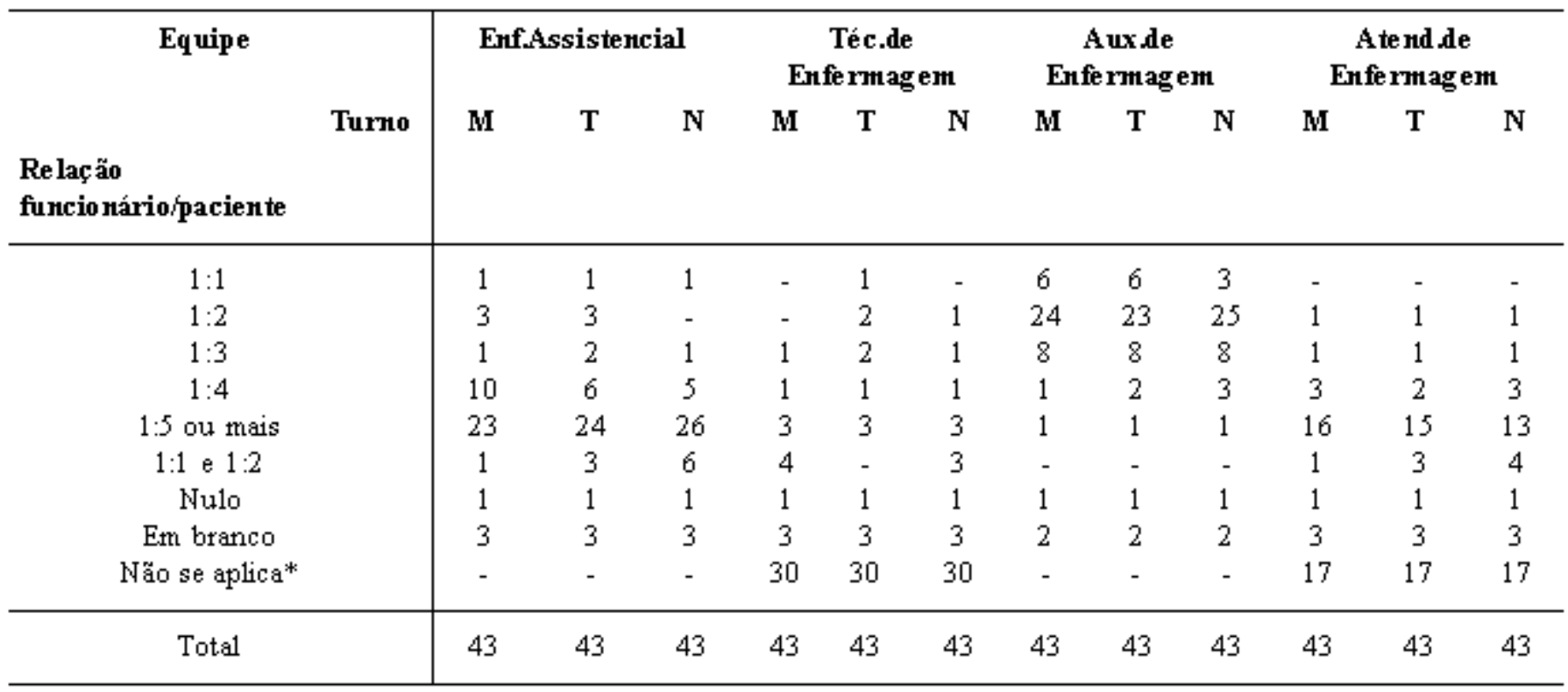

Legenda: $\mathbf{M}=$ Manhã; $\mathbf{T}=$ Tarde; $\mathbf{N}=$ Noite

*Ausência deste elemento

No tocante a distribuição das UTIs segundo a relação numérica entre funcionários da equipe de enfermagem/paciente, a Tabela 3 mostra que para o enfermeiro assistencial esta relação foi de 1:5 ou mais em aproximadamente 24 UTIs, nos 3 turnos de trabalho. Na maioria das UTIs onde existiam técnicos e atendentes de enfermagem foi encontrada esta mesma relação. Entretanto, para o auxiliar de enfermagem a relação foi de 1:2 para, em média, 24 UTIs.

Autores como ALCALA et al. (1977); KOCK \& MULLER(1991); GAUTHIER \& PORAZZO-CARROL (1992) e instituições como Instituto Nacional de Assistência Médica da Previdência Social (BRASIL, 1988) e ASSOCIAÇÃO DE MEDICINA INTENSIVA BRASILEIRA (1995) são unânimes em salientar a necessidade de enfermeiro na UTI durante as 24 horas. Porém, somente GAUTHIER \& PORAZZO-CARROL (1992) é que em um estudo piloto efetuado em 7 hospitais localizados em área metropolitana de Minneapolis em 6 centros médicos, conseguiram identificar em quais condições a relação entre o enfermeiro/paciente é de 1:1. Estas condições relativas ao paciente são as seguintes: os que são submetidos a cirurgias cardíacas, principalmente nas primeiras 12 horas; aqueles que necessitam de balão intra-aórtico; aqueles com hemorragias hemodinamicamente instáveis; os transplantados renais principalmente nas primeiras 24 horas de pós-operatório e os que necessitam de hemofiltração.

A proporção de 1:1 ou 1:3 é citada em pesquisa efetuada por GREENBAUM (1984) em 800 hospitais dos Estados Unidos. Neste estudo são relatados outros componentes tais como: médicos assistentes em $0,2 \%$ a $1,2 \%$ dos hospitais, os técnicos envolvidos com a monitoração hemodinâmica em 1,8\% a 4,3\% dos hospitais e o fisioterapeuta respiratório em $79,2 \%$ a $84,5 \%$ dos hospitais estudados. 
A ASSOCIAÇÃO DE MEDICINA INTENSIVA BRASILEIRA (1995) definiu dentro das normas mínimas para credenciamento de uma UTI a relação entre auxiliar de enfermagem/paciente de 1:2.

Quanto ao salário inicial dos enfermeiros estão representados na Figura 3.

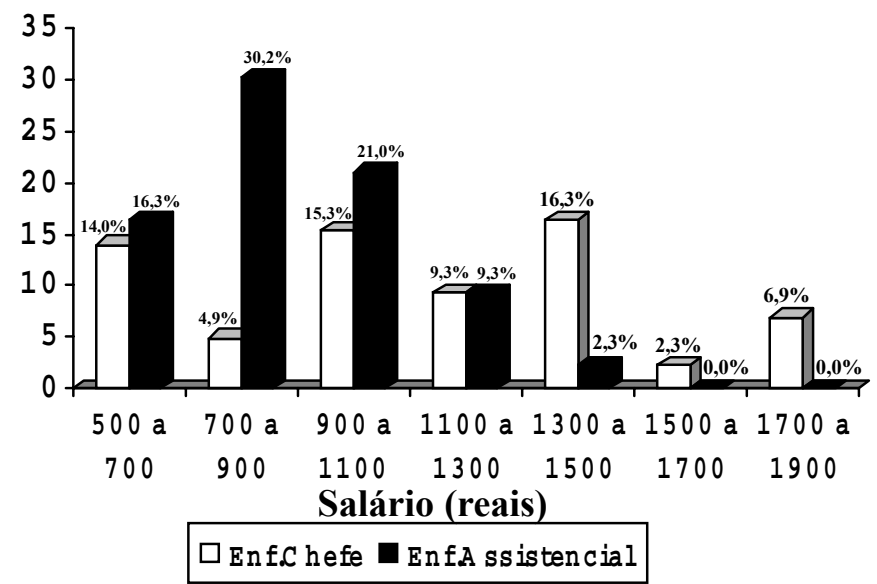

Figura 3 - Distribuição das UTIs segundo salário inicial da enfermeira. São Paulo, 1994/1995

Quanto ao salário inicial da equipe de enfermagem, pela Figura 3 observa-se que em 7 (16,3\%) das UTIs, a faixa salarial da enfermeira chefe variou de 900 a 1100 reais e igual número de UTIs esta faixa salarial variou de 1300 a 1500 reais. Verifica-se ainda, que em 6 $(14,0 \%)$ das UTIs a faixa salarial variou entre 500 a 700 reais e somente $3(6,9 \%)$ das UTIs o enfermeiro chefe percebia salário entre 1700 a 1900 reais.

Em relação ao enfermeiro assistencial, a faixa salarial foi de 700 a 900 reais em $13(30,2 \%)$ das UTIs seguido da faixa salarial de 900 a 1100 reais em $9(21,0 \%)$, sendo que somente em $1(2,3 \%)$ da UTIs esta faixa salarial foi de 1300 a 1500 reais, sendo esta a maior faixa para o enfermeiro assistencial.

Tabela 4 - Distribuição das UTIs segundo salário inicial do auxiliar de enfermagem. São Paulo, 1994/ 1995

\begin{tabular}{l|cc}
\hline Salário inicial (reais) & \multicolumn{2}{|c}{$\begin{array}{c}\text { Auxiliar de Enfermagem } \\
\mathbf{n}^{\mathbf{0}}\end{array}$} \\
\hline $200 \mid----400$ & 12 & $(27,9)$ \\
$400 \mid---600$ & 17 & $(39,5)$ \\
$600 \mid---800$ & 3 & $(7,0)$ \\
$800 \mid---1100$ & 3 & $(7,0)$ \\
Em branco & 8 & $(18,6)$ \\
\hline Total & 43 & $(100,0)$ \\
\hline
\end{tabular}

Já para o técnico de enfermagem somente 11 UTIs responderam, sendo que destes em $6(14,0 \%)$ UTIs o salário foi de 500 a 700 reais e em 1 UTI foi de 700 a 900 reais. Para o auxiliar de enfermagem (Tabela 4), há um predomínio de $17(39,5 \%)$ UTIs em que a faixa salarial foi de 400 a 600 reais e $6(14,0 \%)$ UTIs que a faixa salarial varia de 600 a 1100 reais. Para o atendente de enfermagem houve 22 UTIs respondentes sendo que destas, o maior número de unidades, 15 (34,9\%) UTIs, situou-se na faixa salarial de 100 a 300 reais, seguido de $7(16,3 \%)$ UTIs em que esta faixa foi de 300 a 500 reais.

\subsection{Dados relacionados à caracterização do enfermeiro}

Esses dados estão resumidos no Quadro 1 abaixo.

Quadro 1 - Caracterização dos enfermeiros das UTIs do município de São Paulo, 1994/1995

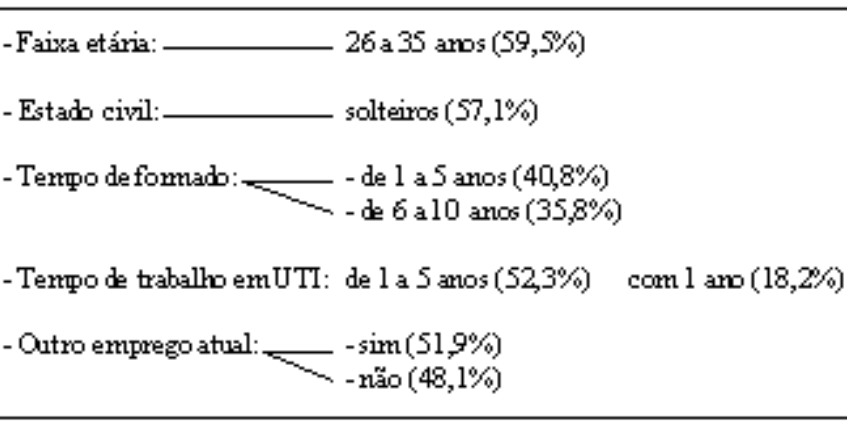

Quanto aos dados de caracterização dos enfermeiros, observa-se que a faixa etária predominante foi de 26 a 35 anos (59,5\%), e em relação ao estado civil $57,1 \%$ eram solteiros (Quadro 1).

Em relação ao tempo de formado dos enfermeiros, houve um predomínio de 1 a 5 anos com $40,8 \%$ e de 6 a 10 anos com 35,8\% (Quadro 1).

No que diz respeito ao tempo de trabalho em UTI, mais da metade, $52,3 \%$ trabalhava na área de 1 a 5 anos.

Quanto a informação de estarem trabalhando em outro emprego, a maioria das respostas foi afirmativa $(51,9 \%)$.

Em um Fórum Aberto realizado por MOORE et al. (1993) e publicado na revista Critical Care Nurse da Califórnia, enfermeiras de diferentes instituições de ensino, assistência e pesquisa foram indagadas se elas contratavam recém formadas para trabalhar em UTI. Caso a resposta fosse negativa, qual seria a razão disto e qual seria o conselho que elas dariam a estas recém formadas. Dentre as 9 enfermeiras pesquisadas, 4 delas responderam que contratavam porém, fizeram algumas ressalvas tais como: para algumas das unidades críticas com exceção da unidade de cirurgia cardíaca; somente em unidades de terapia intensiva pediátrica, após pelo menos 3 a 6 meses de treinamento; que elas começassem a assumir gradativamente e não repentinamente; somente após orientação de 2 meses em clínica médico-cirúrgica e 2 a 
6 meses de treinamento na UTI. As que não contratavam justificaram dizendo que elas preferiam enfermeiras experientes nesta área; para atuar nesta área não bastava ter conhecimento e experiência restritos a livro texto e aos cuidados básicos. Os conselhos dados foram que não recomendavam as recém formadas ir diretamente para uma UTI, mas que tivessem experiência de interagir com pacientes e ao mesmo tempo melhorar o seu desempenho, atuando em unidades de internação de clínica médicocirúrgica para ir se aperfeiçoando e serem capazes de cuidar de pacientes críticos. Mesmo uma delas que teve a oportunidade de ir para a UTI recém formada e que se sentiu confiante, por ter tido esta experiência no último semestre de graduação não recomenda ao recém formado tal opção porque sentiu que a equipe assistencial da unidade considerava-a muito nova para aquela tarefa.

Quadro 2 - Formação dos enfermeiros das UTIs do município de São Paulo após a Graduação. São paulo, 1994/1995

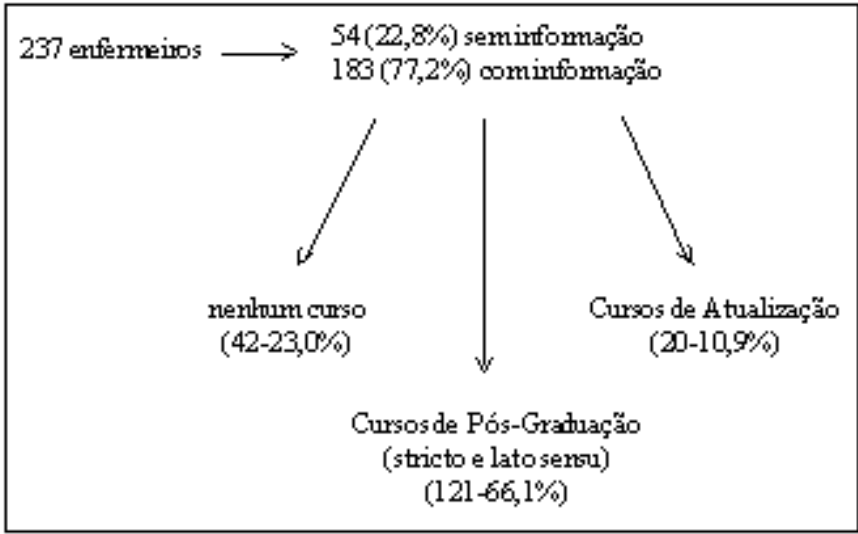

No tocante à formação dos enfermeiros após a graduação (Quadro 2), dos 183 (77,2\%) enfermeiros que forneceram informações, a maioria $121(66,1 \%)$ freqüentou cursos de Pós-Graduação (stricto e lato sensu) e $20(10,9 \%)$ cursos de atualização. Entretanto, 42 $(23,0 \%)$ dos enfermeiros não fizeram nenhum curso.

Segundo SUTCLIFFE (1993) em seu estudo que tinha como objetivo investigar se havia preferência nas estratégias de ensino de acordo com o assunto a ser abordado, entre os enfermeiros de um curso de Especialização Cárdiopulmonar, ressaltou em uma das suas conclusões a importância da junção da teoria com a prática, lembrando que os docentes devem constantemente atualizarem-se com a prática e os enfermeiros com a teoria.
Tabela 5 - Enfermeiros de UTI segundo tipos de Cursos de Pós-Graduação freqüentados (lato e stricto sensu). São Paulo, 1994/1995

\begin{tabular}{|c|c|c|c|}
\hline Tüpos de cursos & $\mathbf{n}^{0}$ & $\%$ & \\
\hline $\begin{array}{l}\text { - Especialização/aprimoramento } \\
\text { em Enfermagem Médico- } \\
\text { Cirúrgica }\end{array}$ & 46 & 38,0 & \multirow{3}{*}{$\begin{array}{l}119 \\
(98,4 \%)\end{array}$} \\
\hline $\begin{array}{l}\text { - Especialização/aprimoramento } \\
\text { em outras áreas }\end{array}$ & 43 & 35,6 & \\
\hline $\begin{array}{l}\text { - Especialização/aprimoramento } \\
\text { em Enfermagem Médico- } \\
\text { Cirúrgica e outras áreas }\end{array}$ & 15 & 12,4 & \\
\hline $\begin{array}{l}\text { - Especialização/aprimoramento } \\
\text { em áreas não identificadas }\end{array}$ & 15 & 12,4 & \multirow{3}{*}{$\begin{array}{l}2 \\
(1,6 \%)\end{array}$} \\
\hline - Mestrado & 1 & 0,8 & \\
\hline $\begin{array}{l}\text { - Mestrado e especialização/ } \\
\text { aprimoramento em } \\
\text { Enfermagem Médico-Cirúrgica }\end{array}$ & 1 & 0,8 & \\
\hline Total & 121 & 100,0 & \\
\hline
\end{tabular}

Pela Tabela 5 nota-se que dos 121 enfermeiros que fizeram curso de Pós-Graduação, 119 (98,4\%) frequentaram curso de especialização / aprimoramento, sendo que a grande maioria na área de Enfermagem Médico-Cirúrgica (KOIZUMI et al., 1998).

$\mathrm{O}$ fato de enfermeiros que atuam em UTI freqüentarem cursos de Pós-Graduação tem nos mostrado dois pontos positivos. O primeiro é que estes cursos estimulam a elaboração de pesquisas, geralmente de questões da vivência prática; e segundo, que por atuarem na área assistencial, a possibilidade de implementação dos resultados das mesmas é maior.

Na literatura NEWMAN et al. (1989), integrantes de um Comitê de Pesquisa em UTI, da Flórida, não concordam integralmente com o segundo ponto acima citado, descrevendo que a aplicação dos achados das pesquisas na prática, tem sido muito difícil, a começar pela dificuldade de aceitação de mudanças. Porém, defendem a importância de se ter um Comitê de Pesquisa nas UTIs apontando duas finalidades: uma de que as pesquisas podem dar respaldo a muitas atividades clínicas de enfermagem e desta forma indiretamente o reconhecimento profissional pela qualidade da assistência prestada; e a outra é a importância do envolvimento não só das supervisoras mas também da equipe de enfermagem no desenvolvimento das pesquisas e que talvez esta seja a forma de facilitar a implementação dos resultados das mesmas na prática clínica. 
CONCLUSÕES

Este estudo permitiu as seguintes conclusões:

Quanto à composição da equipe assistencial verificou-se que: o auxiliar de enfermagem foi o profissional presente em 41 das 43 UTIs, seguidos do médico em 39 UTIs e do enfermeiro assistencial em 35 e o enfermeiro chefe em 31 UTIs. Em termos quantitativos de elementos da equipe e turnos de trabalho a ordem foi semelhante, aparecendo o auxiliar de enfermagem, o médico e o enfermeiro assistencial respectivamente com $912(54,4 \%), 218(13,1 \%)$ e $211(12,6 \%)$ elementos, sendo que a equipe de enfermagem totalizou 1328 elementos correspondendo a $79,2 \%$ da equipe assistencial.

Quanto à equipe de enfermagem verificou-se que: com exceção do enfermeiro chefe que em 18 (41,9\%) UTIs tinha uma jornada de trabalho semanal de 40 horas, os demais elementos da equipe de enfermagem tinham uma carga horária semanal de 36 horas na maioria das UTIs; quanto a presença ou não do rodízio, a grande maioria $32(74,4 \%)$ UTIs o enfermeiro chefe fazia rodízios e para os demais elementos da equipe de enfermagem houve um predomínio de UTIs que não faziam rodízio; no que tange a duração dos turnos de trabalho, o enfermeiro chefe de 19 (44,2\%) UTIs tinham a duração da jornada de trabalho de 8 horas, e para igual número de UTIs, a duração do turno de trabalho do enfermeiro assistencial foi de 6/6/12 horas (manhã, tarde, noite); quanto a relação numérica entre funcionário da equipe de enfermagem/paciente, para o enfermeiro assistencial foi de 1:5 ou mais em aproximadamente 24 UTIs, nos 3 turnos e para o auxiliar de enfermagem a relação foi de 1:2, em média, em 24 UTIs, nos 3 turnos; no tocante ao salário inicial, para o enfermeiro chefe a faixa salarial foi bastante variável havendo um predomínio nas faixas de 900 a 1100 reais e de 1300 a 1500 reais em 7 (16,3\%) UTIs em cada uma destas, para o enfermeiro assistencial a faixa salarial de 900 a 1100 reais foi onde houve um predomínio, seguida da faixa salarial de 900 a 1100 reais, respectivamente em 13 $(30,2 \%)$ e $9(21,0 \%)$ UTIs, para o técnico de enfermagem a faixa salarial em que a maioria $6(14,0 \%)$ UTIs respondentes citou que foi a de 500 a 700 reais, para o auxiliar de enfermagem $29(67,4 \%)$ UTIs a faixa salarial variou de 200 a 600 reais; e para o atendente de enfermagem a maioria $15(34,9 \%)$ UTIs citou que foi a de 100 a 300 reais.

Quanto a caracterização do enfermeiro verificouse que: a faixa etária predominante foi de 25 a 35 anos (59,5\%); em relação ao estado civil, $57,1 \%$ eram solteiros; houve um predomínio de tempo de formado de 1 a 5 anos com 40,8\%; mais da metade (52,3\%) trabalhando em UTI de 1 a 5 anos; a maioria (51,9\%) tinha outro emprego; dos que forneceram informação, $66,1 \%$ freqüentaram curso de Pós-Graduação (stricto ou lato sensu), sendo que destes 98,4\% foram curso de Especialização e Aprimoramento com um grande número na área de Enfermagem Médico-Cirúrgica; 23,0\% não fizeram nenhum curso após a graduação.

\section{HUMAN RESOURCES OF THE INTENSIVE CARE UNITS FROM THE MUNICIPAL DISTRICT OF SÃO PAULO}

The study had the purpose to investigate aspects of the ICUs from the Municipal district of São Paulo, regarding the composition of the clinical staff; characteristics of the nursing personnel and nurses' characterization. Data were collected through 47 questionnaires distributed in 32 hospitals. Results show that: the morning and the afternoon shifts have a larger number of people from all clinical categories, the majority of the nursing personnel work 36 hours per week, nurses' wages varied from 700 to 1,500 "reais" and 66.1\% of them were enrolled in Master Programs. Authors concluded that 79,2\% of the clinical staff was formed by the nursing personnel.

KEY WORDS: human resources, intensive care unit (ICU)

\section{RECURSOS HUMANOS EN LAS UNIDADES DE CUIDADOS INTENSIVOS DEL MUNICIPIO DE SÃO PAULO}

El estudio tuvo como objetivo investigar aspectos de las UCIs (Unidades de Cuidados Intensivos) del Municipio de São Paulo, en lo que se refiere a la composición del equipo asistencial; características del equipo de enfermería y de la caracterización de los enfermeros. Los datos fueron recolectados a través de 47 cuestionarios distribuidos en 32 hospitales sorteados. Los resultados muestran que: los periodos de la mañana y de la tarde contaron con mayor numero de personas de todas las categorías del equipo asistencial, la mayoría del equipo de enfermería tienen jornadas de trabajo de 36 horas semanales, la remuneración del enfermero varió de 700 a 1500 reales y que 66,1\% frecuentaron el curso de Pós-grado. La conclusión es que el equipo de enfermería corresponde a 79,2\% del equipo asistencial. 


\section{REFERÊNCIAS BIBLIOGRÁFICAS}

01. ALCALA, M. U. et al. Estudo preliminar para estabelecimento de quadro de pessoal de enfermagem na superintendência médico hospitalar de urgência. São Paulo: Secretaria de Higiene e Saúde da Prefeitura do Município de São Paulo, 1977. 47p.

02. ASSOCIAÇÃO DE MEDICINA INTENSIVA BRASILEIRA (AMIB). Normas mínimas para credenciamento de uma unidade de terapia intensiva. São Paulo, 1995.

03. BRASIL. Leis etc. Lei $n^{\circ} 7498$ de 25 de junho de 1986. Dispõe sobre a regulamentação do exercício da enfermagem e dá outras providências. Diário Oficial da União, Brasília, 26 jun.1986. Secção 1, p. 9273-5.

04. BRASIL. Ministério da Previdência e Assistência Social. Secretaria de Medicina Social. Enfermagem - Contribuição para um cálculo de recursos humanos na área. Rio de Janeiro: Coordenadoria de Comunicação Social/ INAMPS, 1988. 44p.

05. CARLSON, R. W. Seizing the initiative (quest editorial). Heart \& Lung, v. 18, n.5, p. 433-5, 1989.

06. GAUTHIER, R. N.; PORAZZO-CARROLL, J. Criteria for 1:1 nursing care. Critic. Care Nurse, v. 12, n. 7, p. 91-4, 1992.
07. GOMES, A.M. Enfermagem na Unidade de Terapia Intensiva. 2. ed. São Paulo: EPU, 1988.

08. GREENBAUM, D.M. Availability of critical care personnel, facilities, and services in the United States Critic.Care Med., v. 12, n. 12, p. 1073-8, 1984.

09. KOCK, R.M.; MULLER, L. Situação do exercício da enfermagem nos hospitais do Paraná. Rev. Bras. Enfermagem, v. 44, n. 2/3, p. 31-42, 1991.

10. KOIZUMI, M.S. et al. Educação continuada da equipe de enfermagem nas UTIs do Município de São Paulo. Rev.latino-am.enfermagem, v. 6, n. 3, p. 33-41, 1998.

11. MOORE, M.L. et al. Are new graduates hired in your unit? If not why not? What advice would you give them? Critic. Care Nurse, v. 13, n. 5, p. 126-7, 1993.

12. NEWMAN, L.S. et al. Critical care voices: application of research in clinical practice. Dimens. Critic. Care Nurs., v. 8, n. 6, p. 364-6, 1989.

13. PIMENTEL, M.L. et al. A força de trabalho em Enfermagem no Estado de São Paulo. São Paulo: Conselho Regional de Enfermagem de São Paulo e Associação Brasileira de Enfermagem de São Paulo, 1996.

14. SUTCLIFFE, L. An investigation into wether nurses change their learning style according to subject area studied. J. Adv. Nurs., v. 18, n. 4, p. 64758, 1993. 